\title{
Self-Medication Among Children Under 5 Years Living in Rural Area, Ferlo Senegal
}

\author{
Ndèye Marème Sougou ${ }^{1,}$, Gilles Boestch ${ }^{2}$, Mouhamadou Makhtar Mbacké Leye ${ }^{1}$, \\ Mayassine Diongue ${ }^{1}$, Ibrahima Seck ${ }^{1}$, Anta Tal-Dia ${ }^{1}$ \\ ${ }^{1}$ Department of Public Health and Preventive Medicine, University Cheikh Anta Diop, Dakar, Senegal \\ ${ }^{2}$ Department of Unité Mixte International 3189, University Cheikh Anta Diop, Dakar, Senegal
}

\section{Email address:}

nmsougou@hotmail.com (N. M. Sougou)

${ }^{*}$ Corresponding author

\section{To cite this article:}

Ndèye Marème Sougou, Gilles Boestch, Mouhamadou Makhtar Mbacké Leye, Mayassine Diongue, Ibrahima Seck, Anta Tal-Dia. SelfMedication Among Children Under 5 Years Living in Rural Area, Ferlo Senegal. Central African Journal of Public Health.

Vol. 3, No. 6, 2017, pp. 110-114. doi: 10.11648/j.cajph.20170306.13

Received: October 26, 2017; Accepted: November 20, 2017; Published: December 14, 2017

\begin{abstract}
In African rural area, self-treatment has its place in the devices of therapeutic choices. The aim of this study was to determine the extent and pattern of self-treatment among children living in Senegal rural area. A cross-sectional study was carried out to examine the place of self-treatment in the stages of the therapeutic itinerary among children living in Senegal rural area in March 2017. Using Schwartz formula for sampling, we had included in this study 173 children aged 6 to 59 months living in the area of Widou Thiengoly. Mothers were interviewed on the therapeutic itinerary chosen in case of children disease. Bivariate and multivariate analyses were made. Most of children (82.3\%) lived on more than 1 hour drive from health facility. For the first instance of therapeutic choice, most of mothers (61.2\%) used self-medication in case of children disease, $35.3 \%$ of mothers used health facilities and $2.6 \%$ choosed traditional healers. For second instance, only $2.4 \%$ of mothers were used self-medication. For third instance, there was no self-treatment. Therapy organizing group were led by mothers at $56.5 \%$ and fathers in $45.6 \%$. At $77.6 \%$ of cases, there were discussions to decide on the treatment of the child. In most cases, fathers were interviewed $(90.9 \%)$ to give their opinion on the therapeutic choice. Fathers paid for children care in $87.6 \%$ of cases. $30.6 \%$ of mothers said that self-medication was cheaper compared to health facilities and traditional healers. $95.3 \%$ said that they believed that it was most efficiency to use a lot of type of therapeutic in same moment. Multilogistic regression found that living away from health facility (more than 30 minutes) was positively correlate with self-treatment $\mathrm{p}<0.01$, ORaj $=5.39 \mathrm{IC}=$ [1.42-24.26]. This study contributes to the knowledge of self-treatment choices regarding children disease management in Senegal rural area. This study shows that geographical inaccessibility of health facilities impact on self-medication practices in rural area.
\end{abstract}

Keywords: Self-Medication, Children, Rural Area, Senegal

\section{Introduction}

In Senegal, the search for care for sick children is intimately linked to self-treatment practice and low use of health facilities [1]. In the "Sénégal-Analyse globale de la vulnérabilité, de la sécurité alimentaire et de la nutrition" (AGVSAN) report [2], we note that with most children living in villages in Senegal, the initial care begins with selfmedication at the expense of the use of health facilities. Selfmedication refers to all practices related to "self-care", through "products" or practices to improve health without the use of a health professional. The diversity of therapeutic offers is a proven fact in the contemporary world. It refers to a cosmopolitan therapeutic space. In Africa, there is a wide range of therapeutic remedies, ranging from modern medicine to traditional medicine, through cults healing Jewish-Christian or prophetic or maraboutic practices. Beside these possibilities of recourse, are added the popular 
practices of care whose main actors are the mothers, the fathers, the grandmothers and grandfathers, but also all the peddlers of medicines (modern or traditional) sold at the detail through African towns and villages [3]. The success of this therapeutic pluralism in Africa is commensurate with the health system crisis and, more generally, with the crisis in African states [4]. Self-medication is often the first step in treatment [5]. Many studies concern self-medication, but very little has been done in self-medication among young children in rural Africa. The main of this article is to analyze the place of self-medication among children in a rural environment in Ferlo, Senegal.

\section{Materials and Method}

\subsection{Study Area and Population}

This study was made in Widou Thiengholi. Widou is an area located in the department of Linguère in the Ferlo of Senegal. This zone is the seat of the implantation of the great green wall. The number of inhabitants of the Widou Thiengoly area is estimated at about 5,200 people [6]. The majority of Widou's population is nomadic Fulani whose encampments revolve around the Widou borehole. The study looked at children under 5 living in the study area. The children under 5 years old were included in the study. Children fewer than 5 whose parents refused to answer questions and those who were not found in households were excluded from the study.

\subsection{Type of Study}

A cross-sectional study for descriptive and analytical purpose was used to assess practices of self-medication among children less than 5 years.

\subsection{Sample Size Determination and Sampling Technique}

A representative sample size of 173 was obtained using formula for descriptive study design [7], $\mathrm{n}=\mathrm{Z} 2 \alpha \times \mathrm{pq} / \mathrm{d} 2$ where $n$, is sample size; $Z \alpha$ is standard normal deviate at alpha error corresponding to confidence value of 1.96 ; $p$ is the proportion of factor of interest under study in the previous study and $q$ is complimentary probability of $\mathrm{p}$ while $\mathrm{d}$ is level of precision set at alpha value of 5\% (0.05) [7]. In Widou, the child population is estimated at 988 (19\% of 5200 people living in Widou). Nineteen percent $(19 \%)$ is the size of the child population in Senegal. In Linguère, department, the prevalence of malnutrition is $12.3 \%$ according to the SMART survey. The selection of the prevalence of malnutrition as the basis for sampling (p) is linked to the fact that it is one of the leading causes of morbidity and is associated with $50 \%$ of the causes of death among children under 5 in Africa [8]. Taking into account the number of non-respondents, the total sample size is 170 children. The questionnaires were administered to the mother of each child included in the sample. Thus 170 mothers of children under 5 were surveyed.

For sampling technique, household were selected using simple random sampling technique method (Balloting technique). Where in the selected house, the eligible person refused to participate, the next sampling unit was selected.

\subsection{Data Collection and Analysis}

The survey was done in 2017 by 3 investigators speaking the vernacular language of the area which is fulbé. The questions concerning the therapeutic routes were thus asked to the Fulbe mothers. Mothers and their children were all found in the household.

Data analysis was done using $\mathrm{R}$ studio software version 3.1.3. The mean and standard deviation was calculated for the continuous data while the categorical data were expressed in frequency and percentages. Multivariate logistic analysis was made to determine factors associated with selfmedication. Variables included in the model were sociodemographic variables, type of household, type of organization of the therapy organizing group and the organization of the modern local health care system.

\subsection{Ethical Consideration}

Prior to the commencement of the study approval had been obtained from the University Cheikh Anta Diop Local Research Ethics Committee (Reference: Protocol 074/2015/CER/UCAD).

\section{Results}

\subsection{Sociodemographic Characteristics of the Population}

In our sample, the average age of the mothers was $28.1+/-$ 8.01 years; the average age of the fathers was $38.35+/-9.1$ years. Ninety eight percent $(98.8 \%)$ of mothers are married. Seventy three $(72.94 \%)$ of target children were between 24 and 60 months old.

Eighty-two percent $(82.25 \%)$ of the sample take more than one hour to reach the nearest health facility.

Table 1. Description of the time taken to reach the nearest health facility.

\begin{tabular}{lll}
\hline Time Set to Join the Health Structure & Frequency & Percentage \\
\hline 1- Less than 30 minutes & 18 & $10,65 \%$ \\
2- Between 30 min and 1 hour & 12 & $7,10 \%$ \\
3- 1 hour & 22 & $13,02 \%$ \\
4-More than 1 hour & 65 & $38,46 \%$ \\
5- More than 2 hours & 52 & $30,77 \%$ \\
\hline
\end{tabular}

\subsection{Description of the Group Organizing Care}

In $56.5 \%$ of cases, it is the mother who decides that the child needs care. In most cases $(77.6 \%)$, there is a discussion in the family about the therapeutic choice. This discussion mainly concerns the father in $90.9 \%$ of the cases. It is noted that care is paid by fathers in $87.6 \%$ of cases. 
Table 2. Description of the Therapy Organizing Group.

\begin{tabular}{|c|c|c|}
\hline & Absolute frequency (n) & Relative frequency (\%) \\
\hline \multicolumn{3}{|c|}{ Leader of the therapy organizing group } \\
\hline Mother & 96 & 56,5 \\
\hline Father & 77 & 45,3 \\
\hline Grand-mother & 8 & 4,7 \\
\hline Grand father & 1 & 0,6 \\
\hline \multicolumn{3}{|c|}{ Existence of discussion about therapeutic choice } \\
\hline Yes & 132 & 77,6 \\
\hline \multicolumn{3}{|c|}{ Parents involved in discussions about therapeutic choices } \\
\hline Father & 120 & 90,9 \\
\hline Mother & 23 & 17,4 \\
\hline Grand-father & 19 & 14,4 \\
\hline Grand-mother & 2 & 1,5 \\
\hline \multicolumn{3}{|c|}{ Parents involved in the payment of child care } \\
\hline Father & 149 & 87,6 \\
\hline Grand father & 3 & 1,8 \\
\hline
\end{tabular}

\subsection{Description of Therapeutic Itinerary}

In most cases (61.8\%), at the first resort the preferred choice of the population is self-medication. As a second recourse, the health post is more used (84.1\%). At the third level, there is still a better use of modern health posts $(84.7 \%)$ and hospitals $(23.5 \%)$.

There is a therapeutic wandering in $95.3 \%$ of cases. They believe that it's most efficiency to use a lot of type of therapeutic in same moment.

Table 3. Description of Therapeutic Routes.

\begin{tabular}{lll}
\hline & Absolute frequency (n) & Relative frequency (\%) \\
\hline First resort in case of illness & & 61,8 \\
Self-medication & 105 & 35,3 \\
Health post & 60 & 2,9 \\
Traditional healer & 5 & 84,1 \\
Second resort in case of illness & 143 & 10,6 \\
Health post & 18 & 3,5 \\
Traditional healer & 6 & 1,8 \\
Self-medication & 3 & 84,7 \\
Hospital & & 23,5 \\
Third resort in case of illness & 144 & 19,4 \\
Health post & 40 & 0,6 \\
Hospital & 33 & \\
Traditional healer & 1 & \\
Health case & & \\
\hline
\end{tabular}

\subsection{Multivariate Analysis}

Mom-child dyads living more than $30 \mathrm{~min}$ from the health facility were 5.39 times more likely to use self-medication (ORaj $=5.39$ CI: $1.42-24.26$ ).

Table 4. Multivariate analysis.

\begin{tabular}{llll}
\hline & P & ORaj & CI \\
\hline Mother's age & 0.99 & 0.45 & $0.12-1.51$ \\
$\geq 45$ years & & 1 & NA \\
$<45$ years & 0.99 & & \\
Marital status (maried) & & & $0.19-20.20$ \\
Yes & 0.55 & 1.94 \\
No & & 1 & $0.47-11.52$ \\
Type of household & 0.35 & 2.10 & \\
Polygamous & & & \\
Ponogamous & & & \\
No & & & \\
Yes & & & \\
\hline
\end{tabular}




\begin{tabular}{|c|c|c|c|}
\hline & $\mathbf{P}$ & ORaj & CI \\
\hline Child sex & 0.78 & & \\
\hline Female & & 0.91 & $0.45-1.80$ \\
\hline \multicolumn{4}{|l|}{ Male } \\
\hline Existence of discussion about the type of care & 0.99 & & \\
\hline Yes & & NA & \\
\hline \multicolumn{4}{|l|}{ No } \\
\hline Mother leader group therapy organizer & 0.47 & & \\
\hline Yes & & 0.65 & $0.19-2.06$ \\
\hline No & & 1 & \\
\hline Father Leader Group Therapy Organizer & 0.25 & & \\
\hline Yes & & 0.48 & $0.14-1.56$ \\
\hline Non & & 1 & \\
\hline Belief in the effectiveness of several remedies & 0.52 & & \\
\hline Yes & & 2.68 & $0.09-78.69$ \\
\hline No & & 1 & \\
\hline Transhumance family & 0.25 & & \\
\hline No & & 0.66 & $0.32-1.32$ \\
\hline Yes & & 1 & \\
\hline Time to join the structure (more than 30 minutes) & $0.01 *$ & & \\
\hline Yes & & 5.39 & $1.42-24.26$ \\
\hline No & & 1 & \\
\hline Presence of health structure in the housing area & 0.65 & & \\
\hline Yes & & 2.17 & $0.05-81.76$ \\
\hline No & & 1 & \\
\hline
\end{tabular}

NA: Non applicable.

\section{Discussion}

The collective approach in the management of child health induces a long decision-making process, a confrontation of knowledge that favors self-treatment [9]. In our study, in $77.6 \%$ of the cases, there was within the families, a process of consultation leading to the therapeutic decision. This discussion mainly concerns the father in $90.9 \%$ of the cases. It is noted that care is paid by fathers in $87.6 \%$ of cases. However, we note in our study that in $56.5 \%$ of cases, it is the mother who decides that the child needs care. Studies in Africa have shown that women participating in health care decisions $[10 ; 11]$. In general, self-medication has its place in the devices of therapeutic choices. Thus it is not uncommon for a user in Africa to go directly to a private pharmacy and find his happiness. This is the case in the study by Hounsa A. et al which raises the problem of modern self-medication through antibiotics in Abidgan [5]. Self-medication is usually the first step of treatment. If it does not succeed, the patient turns separately, simultaneously or alternatively generally to traditional healers, religious, health facilities [12]. Therapeutic choice is determined by cognitive models that have long been studied according to Keith J.1997 [13]. According to him, the first therapeutic recourse is explained by belief patterns that are subject to the expressed need and to the benefits and risks of treatment. We realize that at first resort, most families choose self-medication as the first therapeutic remedy $(61.8 \%)$, followed by the health post $(35.3 \%)$ and then the traditional health practitioner $(2.9 \%)$. In Africa, numerous studies have shown the predominance of self-medication on other types of treatment $[14,15]$. In Senegal, the results of Franckel (2004) show an intense practice of home care and a low use of health facilities [1].
Similarly, Faye S. et al (2004) shows that in Senegal, selftreatment is the first response to childhood diseases [9]. The high price of drugs at the community level would influence patients' attitudes towards the drug [16]. Thus, it is recommended to take into account the context of poverty and vulnerability of patients in setting up treatment at the community level. For some authors in Mali in particular, the low income of the poor leads to reducing to a strict minimum the use of modern health centers and to favor alternative solutions such as self-medication and the use of traditional medicine because modern medicine often costs very expensive [17]. In Senegal, parents usually give credit to biomedicine but their financial precariousness predisposes them to use self-medication to the detriment of the health structure [9]. Ndir in Senegal shows that the main reason given for self-medication is the lack of financial means [18]. However, the main determinant of self-medication at first resort is the geographical inaccessibility of modern health care facilities, in this case the health post. The results of our study challenge the geographical access of health structures in rural areas. Only $10.65 \%$ of patients live within 30 minutes of the nearest health facility. Living more than 30 minutes from the nearest health facility favors the use of selfmedication as the first use of care in children $p=0.01$ ORaj $=5.39$ [1.42-24.26]. Other studies have found the influence of the accessibility of health structures in the definition of therapeutic routes $[17 ; 19]$. In Mali, for example, Coulibaly et al (2003) concluded that the geographical accessibility of health facilities in addition to the other elements involved in the provision of health services influences the therapeutic choice of patients [19]. Nikiema et al shows in their study in Burkina Faso that the proximity of a public health care structure and the quality of the services offered explain the more or less frequent use of care provision [20]. According 
to Fleuret S. (2015), self-medication profiles are correlated with the socio-spatial practices of individuals [21]. Other studies show that there is a statistical correlation between the practice of self-medication and elements related to the spatial dimension (Fleuret et al online 2017) [22].

\section{Conclusion}

This article shows the place of self-medication within the system of recourse to care for children in rural Africa. The main determinant of self-medication at first resort is the geographical inaccessibility of modern health care facilities, in this case health posts. It is therefore important in public policies to take into account in the strategies for strengthening the health system, the need to increase the supply of health through geographical accessibility of health structures in rural areas.

The limits of this evaluation are related to the methodology. A mixed estimate with a complementary qualitative approach would have made it possible to explore socio-cultural factors impacting in self-medication.

\section{Funding}

This work was funded the CEA-SAMEF (Centre d'excellence Africain pour la mère et l'enfant).

\section{Competing Interests}

All authors declare that they have no competing interests.

\section{References}

[1] Franckel A. "Les comportements de recours aux soins en milieu rural au Sénégal. Le cas des enfants fébriles à Niakhar Sociologie. Université de Nanterre- Paris X, 2004. Français. $<$ tel-00195109>"2004; thèse.

[2] Rapport provisoire AGVSAN (2010): Principaux facteurs structurels de risque de la malnutrition en milieu rural au Sénégal. Kolda-Sédhiou-Matam-Diourbel-Fatick-Kédougou.

[3] Yoro BM. Pluralisme thérapeutique et recours aux soins en milieu rural ivoirien1: approche méthodologique, Ph.D. Recherches qualitatives. 2012; 31 (1): 47-61.

[4] Canguilhem G. Le normal et le pathologique. 1996; Paris: PUF.

[5] Jacquemot P., « Les systèmes de santé en Afrique et l'inégalité face aux soins ", Afrique contemporaine 3/2012 ( $\left.{ }^{\circ} 243\right), p$. 95-97.

[6] www.eco-consult.com/ferlo/spip2cb7.htlm/article4.

[7] Daniel WW, Editor. Biostatistics: a foundation for analysis in the health sciences. 7th ed. New York: John Wiley \& Sons; 1999.
[8] Unicef. La situation des enfants dans le monde 1998. Résumé la Malnutrition, causes conséquences et solutions. Consulté le 21 octobre 2017. URL: https://www.unicef.org/french/sowc98.

[9] Faye S. L., Lalou R., Adjamagbo A., Soigner les enfants exclusivement à domicile en cas de paludisme en milieu rural sénégalais: un effet de la pauvreté? African Population Studies 2004; 19 (2sA).

[10] Thiombiano BG. Genre et prise de décision au sein du ménage au Burkina Faso. Cahiers québécois de démographie Genre et famille en Afrique Burkina Faso. 2014; 43 (2): 249-278.

[11] Adjiwanou V, LeGrand T. Gender inequality and the use of maternal healthcare services in rural sub-Saharan Africa. Health \& Place 29. 2014; 67-78.

[12] Blitman S., (2006), «L'Afrique malade de ses médicaments », Alternatives économiques, 243: 50- 52.

[13] Keith JP., Weinman J. Perceptions of Health and Illness: Current Research and Applications harwood academic.

[14] Abrahams N, Jewkes R, Mvo Z. Indigenous healing practices and self-medication amongst pregnant women in Cape Town, South Africa. Afr J Reprod Health. 2002; 6 (2): 79-86.

[15] Kalaiselvi S., Kumar G., Ramalingam A. Prevalence of selfmedication practices and its associated factors in Urban Puducherry, India Journal List Perspect Clin Resv. 2014; 5 (1).

[16] Amexo M., Tolhurst R., Barnish G., Bates A. Malaria misdiagnosis: effects on the poor and vulnerable. The Lancet. 2004; 364 (9448): 1896-1898.

[17] Commeyras C., Ndo JR., Merabet O., Kone H., Rakotondrabe FP., Comportement de recours aux soins et aux médicaments au Caméroun. 2006; 16 (1).

[18] Ndir A., Automédication au Sénégal. Thèse Pharma, Dakar, $1990, n^{\circ} 81$.

[19] Coulibaly I., Keita B., Kuepie M., Les déterminants du recours thérapeutique au Mali: entre facteurs socioculturels, économiques et d'accessibilité géographique. Démographies et cultures. 2003; 223-240.

[20] Nikiéma A, Rossier C, Ridde V, Inégalités de l'accès aux soins en milieu urbain africain: le cas de la périphérie nord de Ouagadougou communication à la 6ème conférence africaine sur la population «Population africaine: passé, présent et futur», UEPA, Ouagadougou, Burkina Faso, 2011; 16 p.

[21] Fleuret S. Automédication et territoire: la pertinence de la lecture géographique. Actes des Rencontres Nord/Sud de l'automédication et de ses déterminants. 2015; 119-135.

[22] Sébastien Fleuret, Anne Cécile Hoyez et Juliane Christen, «Un système d'information géographique pour mieux comprendre les pratiques d'automédication», Géocarrefour [En ligne], 91/4 |2017, mis en ligne le 20 mai 2017, consulté le 21 octobre 2017. URL: http://geocarrefour.revues.org/10191; DOI: $10.400 \mathrm{z} 0 /$ geocarrefour. 10191. 